\title{
Improving Secondary School Students Physics Achievement Using Reciprocal Peer Tutoring: A Multi-level Quasi-Experimental Study
}

\author{
Mekbib Alemu ${ }^{1^{*}}$ \\ ${ }^{1}$ Science and Mathematics Education, Addis Ababa University, ETHIOPIA
}

Received 27 June 2019 - Revised 1 December 2019 - Accepted 9 December 2019

\begin{abstract}
The purpose of this study was to test the best mix of reciprocal peer tutoring with direct teaching methods to improve students' achievement in secondary school physics teaching in content-focused and high-stake examination-oriented curriculum. Data was gathered from three equivalent grade- 9 sections and assigned to three different intervention groups in pre-test post-test multi-level quasi-experimental design. The three groups used reciprocal peer tutoring once a week $(N=46)$, twice a week $(N=46)$ and three lessons in a week $(\mathrm{N}=51)$ for 9 weeks in two physics units. Results were that reciprocal peer tutoring helped in improving physics achievement of secondary school students $(R 2=0.316)$ in favour of low achieving $(P=0.001)$ and female students $(P=0.038)$ when it is used as a unilateral pedagogy. The conclusion is that reciprocal peer tutoring used as a unitary classroom pedagogy helped all students and differentially less able and female secondary school students to enhance their physics achievement to some extent without negatively impacting their learning. Further replication research with a comparison group was recommended to find a conclusive evidence if the observed failure of mixing pedagogy persists.
\end{abstract}

Keywords: didactical contract, multilevel quasi-experiment, physics achievement, reciprocal peer tutoring

\section{INTRODUCTION}

Despite the effort to raise enrolment rate for sub-Saharan African nations, very high dropout rates are limiting attainment of universalization of primary education in these countries (Education Strategy Agency [ESA], 2018; Lewin, 2009; MOE, 2015). Mostly this problem is attributed to the low quality and relevance of education to the children's life and the society in general (Beatty \& Pritchett, 2012). Ethiopia, being a sub-Saharan African nation, is having difficulty in maintaining quality of education due to very rapid expansion of education to target $100 \%$ enrolment (Joshi \& Verspoor, 2013). Joshi and Verspoor agreed with others to identify additional problems in the efficiency and also quality of learning and teaching in Ethiopia (Beatty \& Pritchett, 2012; ESA, 2018; Singh, 2014). High demand to cater for expansion of education forced the country to recruit poorly prepared and uninterested teacher candidates (Semela, 2010; Singh, 2014). Semela (2010) indicated that this problem is much more serious in such subjects as in physics. The poor recruitment of teachers from low achievers for physics teaching in secondary schools (Rivkin, Hanushek, \& Kain, 2005; Semela, 2010) and the weak preparation programs in teacher education resulted in problematic physics teaching dominated with didactic teaching (Alemu, Kind, Tadesse, Atnafu, \& Michael, 2017; Shibeshi, Mekonnen, Semela, and Endawoke, 2009) with little attempt to actively involve students in the learning.

Over the past decades Ethiopian Ministry of Education launched several development programmes targeted at enhancing the quality of education in the country Some of the major attempts to enhance the quality of education at primary and secondary school levels implemented at least in the past ten years are: staffing primary and secondary schools with academically competent teachers, strengthening teacher and leaders training, curriculum revision and higher quality textbooks development, and strengthening of classroom management and set up through CPD of teachers (MoE, 2015). With the hope of facilitating active learning and realizing community

(c) 2020 by the authors; licensee Modestum Ltd., UK. This article is an open access article distributed under the terms and conditions of the Creative Commons Attribution License (http://creativecommons.org/licenses/by/4.0/). $\square$ mekbib.alemu@aau.edu.et (*Correspondence) 


\section{Contribution of this paper to the literature}

- Reciprocal peer tutoring in deed helped to enhance secondary school students' physics achievement to some extent without negatively impacting learning even if the pedagogy is introduced in highly didactic directteaching culture.

- Reciprocal peer tutoring guided by principles of co-operative learning, resulted in the improvement of students' physics achievement with greater effect on low achieving and female students, unlike suggestion of non-differential effects in the literature.

- In this study unitary pedagogic implementation resulted in better achievement, even though combined implementation of teaching pedagogies with higher or lower frequency were recommended with no empirical backing by common-sense and literature.

participation in school monitoring and support, classrooms were organized in to cooperative groups, which is locally known as one-to-five networks (Mitchell, 2017; MoE, 2015). H, however, the poor-quality persisted evidencing itself through slow rate of learning progress (Singh, 2014), high rate of students' failure in national exams (Alemu et al., 2017; ESA, 2018), and wider achievement gaps between urban and rural and also female and male students (Joshi \& Verspoor, 2013). However, researchers advocate that what directly results in better students' achievement and learning is an effective teaching (Bryk, Harding, \& Greenberg, 2012). Nevertheless, the aspired quality education could not materialize as teaching effectiveness could not be assured by those poorly prepared and least motivated teachers (ESA, 2018; Rivkin et al., 2005; Semela, 2014; Shibeshi et al., 2009).

The major part of lack of teaching effectiveness in the classroom was due to the adherence of teachers to the lecture method throughout the education system (ESA, 2018; Beatty \& Pritchett, 2012; Singh, 2014). The lecture method, which is locally known as the chalk and talk teaching (Joshi \& Verspoor, 2013; Singh, 2014), coupled with the curricular emphasis on high level content learning (Alemu et al., 2017; Beatty \& Pritchett, 2012) is keeping the student in absolute passiveness and frustration in learning (Joshi \& Verspoor, 2013; Singh, 2014). Keeping on the low status of education is unproductive to the countries future in its endeavour to continue to exist in the economic and political map of the globalized world. Further, it is unfair to the large student population in the classroom to continue with pedagogy that will not contribute to the development of highly needed 21st century skills (Bell, 2010; Dole, Bloom \& Kowalske, 2016) assuring employment in the global market. Unless new pedagogy that transforms the educational quality in this country is introduced and changes starting from the classroom level materialise, students will continue in boredom and lack of motivation to learn and teachers will remain frustrated and stressed in their unsuccessful plight to secure high achievements in the high-stake exams such as national examinations (Fullan \& Langworthy, 2013).

As discussed above, Ethiopian education in general and physics education in particular is wedded with lecturing (direct teaching) (ESA, 2018; Joshi \& Verspoor, 2013; Singh, 2014) of highly contend laden curriculum (Alemu et.al, 2017; Singh, 2014) on one hand, and on the other, there is a policy and educational leaders strong demand for active learning (ESA, 2018; MoE, 2015) through implementing the five-to-one network in the classroom (Mitchell, 2017). The nature of peer tutoring is well suited to these conditions (Neugebauer, Ray, \& Sassenberg, 2016; Topping, 2005) and can be easily implemented without many demands in the classroom change and training of students and teacher in using it in the existing classroom (Dole et al., 2016). The small group network classroom set up for peer tutoring already exists in secondary schools' classrooms (Mitchell, 2017; MoE, 2015) and peer tutoring is known to result in significant improvement in content laden curricular environment. Besides, as peer tutors were observed to tend to mimic their classroom teachers (Topping, 2005), it is believed that its implementation will not be of a significantly different change to the learners in Ethiopian classroom conditions.

The purpose of this study is therefore to introduce test reciprocal peer tutoring which will not require much from the teachers' side and see if it results in successful improvements in students' achievement in the context of content focused curriculum and high-stake examination-oriented classroom environment. Numerous studies had been conducted on peer tutoring in general and reciprocal peer tutoring in particular (Miravet, Ciges, \& García, 2014; Neugebauer et al., 2016; Supanc, Vollinger, \& Brunstein, 2017; Topping, 2005). Therefore, here the aim is not merely to see if reciprocal peer tutoring works, but it is to test if the method brings about the desired outcomes in terms of students' academic achievement when the change takes place from the highly teacher-centred conditions to a student-centred one. Furthermore, many of the studies so far are either in true experiments which lack contextual validities or quasi-experiments lacking internal validities (Piesche, Jonkmann, Fiege, \& Keßler, 2016; Zenelia, Thurstonb, \& Rosethc, 2016). As many scholars advocated, academic achievement is not the product of one proven pedagogy, rather depends on the quality of teaching in which the teacher always has choice in the variety of instructional pedagogies to suit the diverse students' needs and content demands (Miravet et al., 2014; Tella, 2013). Most of the time, research in the study of effectiveness of classroom pedagogy are conducted in comparing the new one with the existing one or some other without attempting to see what will happen when mixing 
pedagogy. Thus, this study will also target to find evidence to justify the extent of utilising peer tutoring along with the conventional instruction in realistic classroom conditions with stratified implementation.

Hence, the three main research questions raised in this study are: How will reciprocal peer tutoring affect secondary school students' physics achievement? Which group of secondary school students benefit the most in enhancing their physics achievement from reciprocal peer tutoring? And how should it be used (as unilateral or mixed method) to have a stronger effect on students' achievement?

\section{LITERATURE}

\section{Definitions and Classifications}

Peer tutoring is one of a peer learning method in which knowledge and skill are acquired as a result of people of status equals or matched companions help each other (Topping, 2005). Peer tutoring provides an opportunity for individualised instruction in which learners acquire new knowledge, repeat and practice a new skill, or clarify a given concept (Utley \& Mortweet, 1997). In peer tutoring non-professional teachers act as support providers and teachers to their peers in whole class teaching, large group learning, in small group or one-on-one instruction. The peer teachers in these situations are referred to as tutors. Those who are receiving the instruction and doing the learning are called tutees.

Peer tutoring is distinguished from other forms of peer learning or cooperative learning in that peers are taking specific roles as tutor or tutee (Topping, 2005). These roles can be fixed in which one with a little bit higher status or prior information always take the tutor role and others always receive the teaching and hence are tutees. In a pair group or small group conditions, roles can be exchanged and therefore we call that kind of peer tutoring a reciprocal peer tutoring (Topping, 2005).

In peer tutoring it is possible that power imbalance among peers may be created over time as tutors act as true knowledge providers and source of final answer while tutees gradually acknowledging the role of knowledge recipient (Miravet et al., 2014). However, exchanging of roles in reciprocal peer tutoring tackles these problems and gives equal opportunity to all the group members of learning by teaching a content (Cheng \& $\mathrm{Ku}, 2009$ ). Furthermore, reciprocal peer tutoring maximizes benefit for learners by providing the opportunity to benefit from both the tutor and tutee roles. Less knowledgeable learners were found motivated to engage in peer tutoring and showed better learning outcomes (Neugebauer et al., 2016). Even though more able tutors may feel at a disadvantage in engaging with less able tutees in a heterogeneous groupings, careful structuring and implementation of principles of cooperative learning ensure equal benefits in reciprocal peer tutoring (Supanc et al., 2017).

Normally reciprocal peer tutoring is used in the same learning program in which peers take responsibility for teaching sequence of a subject content interchangeably (Topping, 2005). In one special occasion, Topping and her colleagues (2013) illustrated a little bit different application of reciprocal peer tutoring in which a pair of peer tutoring students were responsible to tutor different subjects to each other (Topping, Dehkinet, Blanch, Corcelles, \& Duran, 2013). In that experiment, Spanish and British age 9 to 12 years children tutored each other online. The unusual use of reciprocal peer tutoring in the experiment was in fact, the two group of students were tutoring to each other in different subjects: children from Spain tutored their counterparts from Britain about Spanish language and the Britain children tutored back to children from Spain about the English language. The result of this reciprocal peer tutoring was a bit different for the two group of students.

\section{Theoretical Bases}

The use of peer tutoring is theoretically underpinned by Vygotsky's (1978) social construction of knowledge mediated by the use of language and concept of zone of proximal development (ZPD). In peer tutoring settings, both the tutor and the tutee have the opportunity to use common language in conjunction to the specialized language of science to investigate science concepts in a level social plane. This is in contrast to the objectivist science teaching in which the teacher uses highly specialized language of science in precise and unchanging ways of describing the working of the "real world" with the attempt to transfer knowledge directly from the teacher's mind to students' mind (Windschitl, 2002). Under the latter case students are expected to internalize the right explanation of nature and the right way of solving problems and reproduce them in the precise language of the teacher during assessment of learning (Gillies \& Ashman, 2003; Windschitl, 2002).

In addition, learning of new knowledge and new skill occur with in what Vygotsky termed Zone of Proximal Development. In peer tutoring, the ZPD is set by the peer tutor and is not expected to be so high that the tutee feels overwhelmed and frustrated by the gap. Actually, knowledge exchange between peers (Johnson, Johnson, \& Smith, 2007) and co-construction of knowledge (Chi, 2009) are facilitated due to the close academic and social positions of 
those involved in peer tutoring. Instead of with the teacher who has more power than the student, in peer tutoring, learners are motivated in externalization of knowledge differences and internalization of shared or co-constructed knowledge (Neugebauer et al., 2016). Learning in peer tutoring, where the overwhelming academic posture of the teacher is not forcing students to play passive roles, is facilitated because of the classroom environment that allows further knowledge elaboration and elicitation (Cheng \& Ku, 2009; Neugebauer et al., 2016).

\section{Expected Outcomes}

There is mounting evidence for the desirable academic outcomes of peer tutoring. Peer tutoring found to be effective in promoting students' academic knowledge building (Cohen, Kulik, \& Kulik, 1982; Hawkins, Musti-Rao, Hughes, Berry, \& McGuire, 2009; Topping, Peter, Stephen, \& Whale, 2004), psychological development (BowmanPerrott, Burke, Zhang, \& Zaini, 2014), and social learning (Supanc et al., 2017). Topping (2005) interpreted the feeling of increased self-esteem to have resulted in peer tutoring from the opportunity of teaching, being heard, and winning the confidence of others. Schleyer and co-workers (2005) also extended the list of benefits of peer tutoring identifying such psychological treats as the feeling of autonomy, taking responsibility of learning and in general feelings of independence (Schleyer, Langdon, \& James, 2005). Peer tutoring was also identified as a positive influence in the students' development within the social dimension (Johnson \& Johnson, 2009; Supanc et al., 2017). Effect on students' effort to achieve, the quality of their interpersonal relationships, and increment in the quality of communication skills were reported in relation to peer tutoring (Bowman-Perrott et al., 2014; Johnson \& Johnson, 2009). Organizational and leadership capacities of students were also recognized as a result of participation in peer tutoring settings (Supanc et al., 2017).

The more researched and claimed to be the area of better reliable measurement about the contribution of peer tutoring for students learning is academic achievement (Topping, 2005). For instance, Fuchs, Fuchs, \& Karns (2001) demonstrated that peer tutoring participant students' scores were found to be superior than the control groups in standardized tests. Additional supporting evidence was also found in the work of Topping and colleagues, (2004). Furthermore, achievement gains in curriculum-based tests were also obtained in Hawkins et al. (2009) and Bowman-Perrott et al. (2007).

While many studies express the achievement gains due to peer tutoring generally, some other studies attribute the gain to one or the other party in the peer group. Cohen, Kulik, and Kulik, (1982) from a meta-analysis of 65 studies on peer tutoring found that the method benefits both tutor and tutee differentially with academic achievement gains. In the meta-analysis the gain for tutees was somehow more than that for tutors. In another study tutors were found to have the largest gain (Benware \& Deci, 1984). In their new version of reciprocal peer tutoring, Miravet et al. (2014) found that the academic benefit to be different for the two group of students, and the extent of effect to depend on the degree of feedback and support given. Furthermore, the effect of peer tutoring in enhancing academic achievement declines with increasing school levels, with elementary schools with the best increment than middle and high school students. It was also reported that peer tutoring to have stronger effects on social and psychological effects than academic gains (Bowman-Perrott et al., 2014).

Despite all the inconsistent variations as to the degree of effectiveness of peer tutoring, researchers in the area acknowledged that it has more positive effects to all students at all levels of education in bolstering students' academic achievement, psychological, and social learning. Very rare literature suggests the utilization of peer tutoring as a single effective teaching method, unlike the many others who recommend it as an alternative and supplemental approach. Tella (2013), after finding it more effective than explicate teaching independent of the gender differences, recommended the use of peer tutoring as an interchangeable classroom methodology. On the other hand, Miravet et al. (2014) suggested the use of reciprocal peer tutoring in a more frequent manner for the best effect on students learning. However, none of such recommendations were based on strong evidence obtained from a study targeted on the degree of mixing peer tutoring with other instructional approaches.

Peer tutoring, unlike the discussions so far, has also some undesirable outcomes especially when it is implemented spontaneously (Topping, 2005). In general, implementing reciprocal peer tutoring is complicated and demanding to students as they will be simultaneously engaged in academic task of teaching to their peers and also appropriately behaving in the social setting (Chang \& Ku, 2009; Topping et al., 2013). Therefore, in order to effectively and productively utilize peer tutoring, training of students is mandatory (Topping et al., 2013). This makes reciprocal peer tutoring more expensive in terms of curricular time, students' and teachers' time, especially in the curricular environment where content learning is highly emphasized. In reciprocal peer tutoring, tutors are expected to setup a cognitive model of competent performance (Cheng \& Ku, 2009) for less able peers to emulate and benefit from upward social comparisons for self-evaluation (Neugebauer et al., 2016). Furthermore, Topping (2005) attests that managing tutee learning, monitoring their performance, and detecting, diagnosing, correcting, and managing misconceptions and errors are cognitively demanding to the student tutor. From their qualitative analyse, Cheng and $\mathrm{Ku}$ (2009) also found lack of interaction and lower level of engagement being a source of concern to students which they attributed to lack of difference between peer tutoring and non-peer tutoring groups 
in achievement results. It is also possible for peer groups to indulge in lower cognitive learning lacking understanding of what the level of curricular expectations are (Miravet et al., 2014). Topping et al. (2013) suggest that these and other problems associated with peer tutoring can be taken care of with careful organizational considerations.

\section{Pedagogical Change}

When such a change of classroom pedagogy is desired, it should be noted that teachers do not readily adapt it in their teaching unless they are convinced that it is safe and certain to bring about better achievements in their students (Dole et al., 2016). On one hand the overall pressure on teachers to raise the achievement levels in high stake-exams and on the other the conceptual, social, and epistemological challenges teachers face in their attempt to change their classroom practice discourage them from trying student centred and constructivist approaches (Dole et al., 2016; Windschitl, 2002). Hence, it is important for educational research to engage in testing various instructional approaches in contextually valid conditions and bring them to teachers' attentions with assuring characteristics for them to implement in their classrooms.

The criteria for choosing those pedagogical approaches to be implemented in the science classrooms should be those aiming at knowledge building, promoting intellectual continuity over time, and encouraging emotional engagement of students (Dole et al., 2016; Fullan \& Langworthy, 2013; Scott, Mortimer, \& Ametller, 2011). In highstake examination focused conditions, teachers prefer to stay with direct instruction in which they are sure to meet the time and content demands of tests (Grant \& Hill, 2006). Not only teachers but also their students are also comfortable with such apparently "proven" pedagogy to get well prepared to the examinations (Dole et al., 2016). Thus, science education research should come up with pedagogies replacing the conventional teacher-centred pedagogy with those that will not create extra work for the teacher, will not demand extra material or time, supplement the current instruction, and above all benefit all the students (Maheady \& Gard, 2010).

\section{RESEARCH METHODS}

\section{Design}

In this study, data was gathered using multi-level pre-test post-test quasi-experimental design. A multi-level quasi-experimental design is an internally replicated design. In the design the independent variable is applied at different levels for multiple groups instead of using one intervention and another comparison groups (Cleary, Gross, Zaslavsky, \& Taplin, 2012; Handley, Lyles, McCulloch, \& Cattamanchi, 2018). Such selection of a design is demonstrated to have improved the internal and external validity of quasi-experiments (Cleary et al., 2012; Handley et al., 2018; Piesche et al., 2016; Zenelia et al., 2016). In this quasi-experimental design three grade-9 sections out of the five sections taught by the same teacher were selected based on pre-test results and assigned to the three different levels of implementation of reciprocal peer tutoring in combination to business as usual direct teaching methods. According to the national physics curriculum for secondary schools, physics is taught three lessons a week in grade 9 with each lesson (period) having 45 minutes duration. Therefore, the three sections were randomly assigned to use reciprocal peer tutoring in all the three lessons (Experimental-1), in two of the three lessons (Experimental-2), and in only one of the three lessons (Experimental-3) per week for 9-weeks. During the 9-weeks intervention, all the three groups, just like the rest of the grade 9 students in the school, were taught two units. The units taught were: Unit 4: Work, Energy, and Power, and Unit 6: Fluid Statics (Pressure in Liquids). Selection of the units were made by the teachers teaching in the school ( 3 teachers) and they decided to teach Unit 5: Simple machines before the unit of Work, Energy and Power was taught.

\section{The School Setting and Participant Samples}

The intervention was implemented in a sub-urban school found in a town near by Addis Ababa, the capital city of Ethiopia. This secondary school was comprised of 7 sections of grade 9 and 6 sections of grade 10 with a total of 587 students. Students in this school are mainly from factory workers and farming families from the town and nearby agricultural fields. Unlike the other secondary schools, during the study (2016/17 academic year) the intervention school was not using plasma TV for teaching, and therefore, it was conveniently chosen as a school where the entire physics teaching is conducted by the teachers in the school. The three sections included in this study contained 149 grade 9 students and selected on the bases of their pre-test score. Only, those sections who had similar average in the pre-test scores and taught by the individual teacher were selected. Some of the students in these sections were not available during the administration of either the pre- or post-tests ( 6 missing in pre-test and 11 missing in post-test). This reduced the total number of students to 126 . 
The teacher who implemented the intervention in the three sections was given a four-days training (6hrs a day) about the theoretical background, purpose, and technique of handling peer group learning in physics classroom. In addition, the implementing teacher was assisted to develop the first two weeks lesson plans. Further consultations and assistances were also provided to the teacher throughout the intervention. To make sure that the experiment would run as designed, with appropriate mixing in the different classes, all the three sections were observed during most of the 9-weeks intervention.

\section{Data Gathering and Instrument}

Data about grade-9 students physics achievement in the two units were gathered by using pre- and post-tests. Teacher made physics achievement test was developed by the researcher in consultation with two of the teachers (intervention and non-intervention teachers) before the experimentation began. The achievement test was comprised of 20 multiple choice items on the contents of the two units. The fact that Unit 5 was taught before Unit 4 , in the intervention school, helped in validating the achievement test with other schools who already taught Unit 4 and part of Unit 6. After making adjustments and corrections to achievement test based on the validation feedbacks, the same test was used as a pre- and post-test. The pre-test was administered at the end of the week before the beginning of the intervention and the post-test at the end of the 9 th intervention week at the same time in all the classes involved.

\section{Implementation of Reciprocal Peer Tutoring}

Unless the design is well thought of, in cooperative learning situations like peer tutoring, the more able students feel that engagement with the less able student is a waste of time for them (Topping, 2005). Low achieving students also may not have the motivation to participate in peer tutoring conditions as they feel that the active learning conditions in which they have to explicate their inabilities and misunderstandings for judgment by their peers (Ambrose, Bridges, DiPietro, Lovett, \& Norman, 2010; Yorges, 2008) would have detrimental effect on their selfesteem. Students in the three classrooms were organized into small peer tutoring group of 3 based on mixed ability grouping. Yorges (2008) recommended that explicit explanation and discussion of the learning benefits of their participation and also clarifying learning objectives and assessment requirements up front can positively affect student motivation. Therefore, in this intervention, participating students were given orientation by their teacher at the beginning of the intervention regarding how to behave in groups, what academic, social and psychological benefits they will gain, and what expectations and requirements are there for assessment in the units.

To avoid that students acknowledge social status of high and low achiever, and consequently assume permanent positions of knowledge dispenser and recipient, peer tutors roles were regularly exchanged in reciprocal peer tutoring (Cheng \& Ku, 2009; Miravet et al., 2014). In Experimental-1 group, each member played a role of a tutor once each week and consequently 9 times throughout the intervention. In Experimental-2 group, only two of the three group members had this chance of becoming a tutor every week as the third class was dedicated for the teachers direct teaching session. Therefore, every member of Experimental-2 had played the role of a tutor 6 times throughout the 9 intervention weeks. In the case of Experimental-3 this role had been exchanged regularly as in the other groups, but since peer tutoring was implemented only once every week, there were only three chances for every student to assume the tutor role.

During the implementation, the teacher introduced the specific learning objectives at the end of the previous lesson to all students and invited those students who are going to be tutors from each group to meet him in time of their convenience outside of class. In those out of class sessions he further clarified what learning expectations would be there for the following class and assigned reading materials from the textbook and some commonly available resource books. The teacher also made himself available for consultation regarding any content of the lesson to be conducted through peer tutoring. During actual class, peer tutors were given the time to present their lesson to their peers, discuss physics concepts, lead question and answer and also exercise activities within their small peer tutoring groups. The style of presentation and choice of learning activities were left for tutors to choose with encouragement of independent decision making from the teacher. At the beginning of unit 4 , students showed stronger desire for summary of the lesson to be given by the teacher, but the teacher, as he was advised, did not do the summary of lessons handled in the peer tutoring sessions. Instead, he kept on encouraging students to ask their peer tutors if there were difficulties in understanding the contents of the lesson. However, he was always concluding the class by stating the objectives of the next physics session. At the beginning of every session, the teacher took few minutes to revise what has been taught in the previous session, as if he was the one who taught that lesson by himself even if the lesson was his direct teaching or peer tutoring session. After the brief revision, the teacher continued with his lesson if that particular session was his or initiated the peer tutoring.

As Grant and Hill (2006) remarked, teachers are very much influenced by their school culture in implementing innovative pedagogy. Even if the design in this intervention was to have tests (at the beginning and end of the 
Table 1. Comparison of pre-test mean scores of the three groups

\begin{tabular}{|c|c|c|c|c|c|c|}
\hline Group & $\mathbf{N}$ & Mean & Std. Deviation & Std .Error & $\mathbf{F}$ & Sig.(2-tailed) \\
\hline Experimental-1 & 51 & 8.72 & 3.386 & 0.445 & \multirow{3}{*}{0.538} & \multirow{3}{*}{0.585} \\
\hline Experimental-2 & 46 & 8.41 & 3.780 & 0.529 & & \\
\hline Experimental-3 & 46 & 9.19 & 4.353 & 0.592 & & \\
\hline
\end{tabular}

Table 2. Comparison of pre-test and post-test mean scores by group

\begin{tabular}{|c|c|c|c|c|c|c|c|}
\hline Section & Test & Mean & Std. Deviation & Std. Error Mean & $\mathbf{t}$ & df & Sig. (2-tailed) \\
\hline \multirow{2}{*}{ Experimental-1 } & Pre-test & 10.02 & 3.238 & .488 & 3.290 & 43 & .002 \\
\hline & Post-test & 11.98 & 3.246 & .489 & & & \\
\hline \multirow{2}{*}{ Experimental-2 } & Pre-test & 9.83 & 2.881 & .456 & .314 & 39 & .756 \\
\hline & Post-test & 10.08 & 4.615 & .730 & & & \\
\hline \multirow{2}{*}{ Experimental-3 } & Pre-test & 10.93 & 3.158 & .487 & -1.365 & 41 & .180 \\
\hline & Post-test & 10.07 & 4.635 & .715 & & & \\
\hline
\end{tabular}

intervention), the teacher had to give four weekend homework exercises to students on the contents of unit 4 and 6 during the intervention period. These homework exercises were the same to all the experimental groups and other classes taught by the teacher. Neither the data from these activities, nor the effect of the occurrence of the activities on the implementation of peer tutoring were captured and analysed in this study.

\section{Data Analysis}

The pre-test score of the five sections of grade 9 students taught by the intervention teacher was analysed using one-way ANOVA to identify those equivalent groups on physics achievement. Since, no significant achievement difference was obtained between the five groups, simple random sampling was used to select the three intervention groups. Even though the design in this study was to have proportional variation between achievement improvement and the frequency of implementation of reciprocal peer tutoring, the data obtained was found to be mixed up. The mean scores of the two intervention groups were found to be nearly the same while the third group mean become significantly different from the other two. This condition violated the assumption for the presumed linear regression analysis and therefore, statistical analysis such as independent sample t-test and ANCOVA were used instead. In order to see which student sub-group benefited more, pair-wise comparison by gender and achievement level were conducted using independent sample t-test.

\section{RESULTS}

The selection of the three intervention classes, as described before was based on the pre-test result and random selection. The data in Table 1 presents the comparison of the three classes mean scores on the physics pre-test. Even if all the five classes taught by the same teacher took the pre-test and comparison for differences in their mean scores was done including all, here the comparison of only the three classes where the intervention took place was presented. Two of the classes dropped because their mean scores in the pre-test was (M1=7.92, SD1=2.862 and $\mathrm{M} 2=7.89$, SD2=3.104) found to be significantly lower than the other three. In the table below, Experimental-1 is the class where all the three lessons each week were conducted using reciprocal peer tutoring, Experimental-2 is the class used reciprocal peer tutoring in 2 of the 3 lessons in a week, and Experimental- 3 is the class used reciprocal peer-tutoring once a week.

At the beginning of the intervention, there were 149 students in the three classes from which only 143 of them took the pre-test. As can be seen from the table, the pre-test mean scores of all the three classes were high $(\mathrm{M}=8.77$, $\mathrm{SD}=3.81$ ) suggesting that students had prior knowledge of the contents of the two units. Physics as a separate subject is introduced starting from grade 7 in Ethiopian schools. These students therefore, were introduced to the two content areas of physics: Work, Energy, and Power and also Fluid Statics in grades 7 and 8, respectively. Besides, no significant difference was observed $(\mathrm{F}=0.538, \mathrm{P}=0.585)$ among the mean scores of the three intervention classes.

After the intervention with reciprocal peer tutoring was completed, post-test was administered to the students in the three classes in the 10th week. Absenteeism and dropping out are common in Ethiopian schools (MoE, 2015) like many of sub-Saharan African countries (Lewin, 2009) which was reflected in this study as well. As a result, the total number of students whose post test results were considered for analysis were only 126. To see if there were improvements in students' achievement, their pre and post results were compared using paired sample t-test and the result are presented in Table 2 .

As can be seen from the data in Table 2, a very small $(\mathrm{MD}=1.96)$ but statistically significant change $(\mathrm{t}=3.29$, $\mathrm{P}=0.002$ ) has been observed in students' physics achievement between the pre- and post-test and that was for those 
Table 3. Analysis of Covariance for students Post-Test result with Pre-test score as a covariate and students' Gender and Ability Levels as fixed variables

\begin{tabular}{|c|c|c|c|c|c|c|}
\hline Source & $\begin{array}{c}\text { Type III Sum of } \\
\text { Squares }\end{array}$ & df & Mean Square & $\mathbf{F}$ & Sig. & $\begin{array}{c}\text { Partial Eta } \\
\text { Squared }\end{array}$ \\
\hline Corrected Model & $716.908^{a}$ & 6 & 119.485 & 9.165 & .000 & .316 \\
\hline Intercept & 679.866 & 1 & 679.866 & 52.147 & .000 & .305 \\
\hline Section & 135.575 & 2 & 67.788 & 5.199 & .007 & .080 \\
\hline Ability Level & 334.832 & 2 & 167.416 & 12.841 & .000 & .178 \\
\hline Gender & 16.552 & 1 & 16.552 & 1.270 & .262 & .011 \\
\hline Pre-test Score & 50.486 & 1 & 50.486 & 3.872 & .051 & .032 \\
\hline Error & 1551.450 & 119 & 13.037 & & & \\
\hline Total & 16797.000 & 126 & & & & \\
\hline Corrected Total & 2268.357 & 125 & & & & \\
\hline
\end{tabular}

a. R Squared $=.316$ (Adjusted R Squared $=.282$ )

who used reciprocal peer tutoring over the whole 9 weeks period. The changes for twice a week and once a week reciprocal peer tutoring groups were not statistically significant. The apparent very poor learning outcome seem to be consistent with the findings of other researchers (Alemu et al., 2017; Joshi \& Verspoor, 2013; Singh, 2014) after instruction.

The design in this study was with the expectation that reciprocal peer tutoring would improve students' physics achievement in proportional manner to the intensity of usage of the method. But, as can be seen from the results in Table 2, no observable learning has been found in the two mixed intervention groups while a statistically significant improvement was observed in the total reciprocal tutoring class. Therefore, the intended regression analysis seemed inapplicable in this case. Thus, comparison among the three intervention groups was conducted using Analysis of Covariance (ANCOVA). In the subsequent analysis, students' pre-test scores were used as covariates, and gender and achievement levels were considered as fixed variables. First semester result obtained from the school record was used to assign students to the three ability levels. Those students whose first semester physics score was one standard deviation below the mean $(\mathrm{M}=55.69, \mathrm{SD}=14.82)$ were assigned to "Low Ability" group $(\mathrm{N}=15)$. Those students whose first semester physics score was within one standard deviation from the mean were assigned to the "Medium Ability" group $(\mathrm{N}=89)$ and those with higher achievement scores by one standard deviation above the mean assigned to the "High Ability" group $(\mathrm{N}=22)$. The result of the ANCOVA analysis is presented it Table 3.

The model where the effect of being in the different sections (with varying extent of implementation of reciprocal peer tutoring) on students' post-test physics achievement controlling for their pre-test result was found to be statistically significant $(\mathrm{F}=9.165, \mathrm{P}=000)$ with the model explaining for $31.6 \%$ of the total variation in physics achievement. In this analysis, the covariate pre-test score of students was not found statistically significant when the confounding variables Ability Level and Gender were interred into the model. However, the pre-test result was found significant in the analysis when these confounding variables were removed from the model. But then, only $14.1 \%$ of total achievement variance was explained by the model.

Furthermore, in the model, students' Ability Level, as determined from their 1st semester physics score was found to be statistically significant $(\mathrm{F}=12.841, \mathrm{P}=0.000)$ whereas, Gender was not found to be statistically significant $(\mathrm{F}=1.270, \mathrm{P}=0.262)$. Further analysis by inspection of interaction plot revealed that in Experimental-1 group, low ability students made a significant improvement in their achievement compared to all the other students in that group and other groups. Therefore, it can be said that the reciprocal peer tutoring teaching method was successful in helping students with low ability to improve their results better. This finding is partly similar to what Tella (2013) found for Nigerian primary school students. In that study students' ability and gender were found to have effect on students' achievement differences after intervention. However, the current result implies that reciprocal peer tutoring did not differentially enabled students of both sexes to improve their physics achievement.

When pre-test score evaluated at a mean value of 10.26, the adjusted mean values for the three intervention groups were estimated. The estimated means were for Experimental-1 group $M=12.08$ with standard error of the mean equal to $S E=0.603$, for Experimental-2 M=10.26 with $S E=0.634$, and for Experimental-3 M=9.79 with SE=0.622. It is to be recalled that statistically significant change in students' physics achievement was observed only in the case of Experimental-1 group where reciprocal peer tutoring was used for the entire physics lessons in the 9 weeks. To find out if these changes significantly existed, pairwise comparisons were conducted after controlling for the pre-test score. The result of the pairwise comparisons are presented in Table 4. 
Table 4. Pairwise Comparisons of the three intervention groups on post-test mean score after controlling for pre-test

\begin{tabular}{ccccc}
\hline (I) Section & (J) Section & Mean Difference (I-J) & Std. Error & Sig. \\
\hline Experimental-1 & Experimental-2 & 1.818 & .874 & .040 \\
\hline Experimental-1 & Experimental-3 & 2.292 & .869 & .009 \\
\hline Experimental-2 & Experimental-3 & .474 & .892 & .596 \\
\hline
\end{tabular}

The mean of Experimental-1 group which used reciprocal peer tutoring three-times a week in the entire 9 weeks intervention period were found to be statistically significantly higher than both the mixed implementation groups $(\mathrm{F}(2,122)=3.923, \mathrm{P}=0.022)$. Even if, the pre-test score was controlled, no statistically significant difference was observed between the means of the two mixed implementation groups. This means that using reciprocal peer tutoring in a mixed manner with direct instruction is not beneficial to raise students' physics achievement however frequently it is used as suggested in the literature (Miravet et al., 2014; Tella, 2013).

During the ANCOVA analysis, students' ability levels and gender were included into the model and that ability level was found to be significant while gender to be marginally not significant in affecting the post-test physics test result. However, one of the research questions in this study was to see if reciprocal peer tutoring was to help all students to improve their physics achievement. Therefore, further analysis was conducted to find out where significant progress was observed based on students' ability levels and gender by comparing Experimental-1 and 2 groups using independent sample t-test. For this purpose, once again ability levels were determined based on first-semester physics result average as a dividing point between "Lower Ability" and "Higher Ability" groups. This was done to get reasonably good and comparable number of students in the different sub-groups for independent sample t-test. When compared with Higher Ability students', lower ability students in the Experimental-1 group showed significantly larger change $(t(29,47)=3.63, P=0.001)$ in their physics achievement than those in the Experimental-2 group. This means, the significant improvement for Experimental-1 group was mainly due to achievement improvement of lower ability students. Hence, we can say the full implementation of reciprocal peer tutoring differentially helped more students with lower ability to improve their physics achievement.

In the ANCOVA analysis, it is to be recalled that Gender was not found to have significant impact on students' achievement when the whole intervention groups were considered. However, Gender was not found even marginally significant. Therefore, when independent sample t-test comparison between male and female students was conducted for Experimental-1 and Experimental-2 groups, something important was made evident. The progress of Experimental- 1 female students were found to be statistically significant $(t(21,42)=2.13, P=0.038)$ compared to their counterparts in Experimental-2 group while the progress of male students in Experimental-1 and Experimental-2 groups were not significant. Therefore, we can infer from this result that even if the intervention did not show overall significance for Gender related achievement improvement, particularly the full-time implementation of reciprocal peer tutoring has significance towards improving female students' achievement.

\section{DISCUSSION}

\section{Reciprocal Peer Tutoring and Achievement}

There were several reports about the effectiveness of peer tutoring to enhance academic achievement (Cohen et al., 1982; Hawkins et al., 2009; Topping et al, 2004; Zenelia et al., 2016). Recently, from the meta-analysis of researches in the area of peer tutoring, Zenelia and co-workers reported that the positive influence on academic achievement is with a minimum of 0.26 to a maximum of 0.75 effect sizes (Zenelia et al., 2016). The finding in the current study also corroborate this conclusion. At least one of the three groups in which reciprocal peer tutoring was implemented as a unitary pedagogy for 9 weeks showed statistically significant improvement. The fact that the three groups were equivalent during the pre-test came out at least with no declining in their achievement in the post test imply that the reciprocal peer tutoring implemented did not at least negatively affected achievement. Therefore, the conclusion here is that reciprocal peer tutoring in deed helps secondary school students to enhance their physics achievement to some extent without negatively impacting their learning. Hence, looking further to how and to which group of students it has better learning outcomes, implementing peer tutoring is a desirable classroom pedagogy.

\section{Differential Effect of Reciprocal Peer Tutoring}

In fixed role peer tutoring, many researchers found that tutors benefit more from preparation process to teach their peers (Cheng \& Ku, 2009; Topping, 2005). However, the desire to provide equal opportunity involvement for all students (Topping, 2005) and more importantly the knowledge that lower ability students can be motivated and benefit more in active involvement in learning process suggested the use of reciprocal peer tutoring (Neugebauer 
et al., 2016). Tella (2013) also found that reciprocal peer tutoring to be effective to improve students' academic achievement regardless of gender differences. To eliminate the disparity in benefiting from peer tutoring, the implementation of reciprocal peer tutoring was guided by the principles of co-operative learning to ensure equal benefits to all learners (Supanc et al., 2017). Nevertheless, the result obtained suggested that ability levels are more important variables than gender in enhancing students' physics achievement. In addition, the pairwise comparison by gender revealed that at least when reciprocal peer tutoring was used as a unitary teaching method, female students gained more than male students. It is to be recalled that the implementation of reciprocal peer tutoring in the current study was from the background that the dominant teaching culture is teacher centred direct instruction in which the gap between female and male students is widening (Joshi \& Verspoor, 2013; Singh, 2014). Therefore, the conclusion based on this finding could be that the implementation of reciprocal peer tutoring may create the opportunity for less able and female students for meaningful engagement in the learning process and therefore differentially helped them to enhance their physics learning.

\section{MIXED PEDAGOGY IN PHYSICS TEACHING}

The last but most important research question of this study was to see if reciprocal peer tutoring can be mixed with direct teacher-centered teaching method for best students' outcome. Despite empirical evidences and the emphasis on active and student-centered teaching in the numerous training attempts, teachers are predominantly using teacher centered direct instruction (Rivkin et al., 2005; Semela, 2014; Shibeshi et al., 2009). Therefore, the most feasible introduction of student-centered instruction such as peer tutoring is in some combination with the dominant direct instruction. Hence, in this research the attempt was to find out which combination: total, high frequency, or low frequency implementation of peer tutoring that results in better physics achievement. Literature frequently recommended combined implementation of a teaching pedagogy (Dole et al., 2016; Maheady \& Gard, 2010; Windschitl, 2002). Some researchers recommended more frequent use (Miravet et al., 2014) while others recommended intermittent use (Tella, 2013) of peer tutoring. However, none of these recommendations were based on empirical research findings.

In the current study results are in contrast to the recommendations in literature. What we found is that reciprocal peer tutoring is effective in enhancing students' physics achievement when it is used as a unitary pedagogy, not as any combination. While the change in achievement of the group with full implementation of reciprocal peer tutoring, three times a week, for 9 weeks was statistically significant, no such change was observed in the two mixed pedagogy groups. In a way, this finding is in agreement with what Cheng and Ku (2009) found. Cheng and $\mathrm{Ku}$ found that reciprocal peer tutoring group did not show significant difference compared with nonpeer tutoring groups and claimed that this lack of significant effect is due to the weak intensity of the implementation in a course that was taking place only for 50 minutes a week. The mixed implementation of reciprocal peer tutoring in the current research was for about 90 and 45 minutes per week and over 9 weeks. Therefore, this issue of lack of time for students to get used to the method can partly explain the lack of difference. Nevertheless, short time implementation will not totally explain the finding as the change in the academic achievement of students in the 135 minutes (3 lessons) per week was also small but statistically significant. In addition, though it was not statistically significant, the once in a week peer tutoring groups had also showed a little decline in the post test. This finding is not only in contrast to literature and common sense but also something to ponder on what was going on differently in the two pedagogical approach for the data to turn up this way.

In a traditional teacher centered classroom teaching, the teacher sets the learning objectives, makes decisions about the learning activities, presents the lesson, gives instructions of behaviors, asks questions, and usually answers these questions without giving enough time for students to think, and finally summarizes and concludes the lesson. In this condition students are forced to assume more passive roles and believe that they are expected to copy the note from the chalk board and receive the knowledge dispensed by the teacher from the front stage. What the student thinks in this case is that knowledge emanates from the teacher and students' responsibility is to accept that knowledge and memorize it as it is to recite it during assessment. In contrast to this, in peer tutoring students take proactive roles in thinking, questioning, and sharing knowledge (Cheng \& Ku, 2009). Actually, knowledge exchange between peers (Johnson, et al., 2007) and co-construction of knowledge (Chi, 2009; Topping, 2005) are facilitated due to the removal of the teachers' dominant posture and close academic and social positions of those involved in peer tutoring. Here, learners are motivated in externalization of knowledge differences and internalization of shared or co-constructed knowledge (Neugebauer et al., 2016) facilitated because of the classroom environment that allows further knowledge elaboration and elicitation (Cheng \& Ku, 2009; Neugebauer et al., 2016). Under this situation, the teacher is expected to play the role of facilitator and a resource person while students are expected to discover knowledge, reshape it and share it in the conducive social environment.

These different behavioral expectations seemingly governing students and teachers conducts in a classroom, as cited in Arias and Araya (2009) what is termed as by Brousseau (1998) as "Didactical Contract". According to Brousseau, in any instructional conditions there are a set of rules that determines what the students and the teacher 
"have the responsibility to carry on, and what each one is responsible in some way". Normally it is the teacher either explicitly through words or implicitly through gestures, attitudes and silences who establishes them (Arias \& Araya, 2009). Thus, students knowingly or unknowingly endorse the contract and will abide by them while learning. According to the theory of didactical contract (Pepin, 2014) once the rules are established and endorsed neither the teacher nor the student perform and act of breaching the contract without consequences.

In this research, we can assume that there were two set of didactical contacts: one for the teacher centred classroom where the teacher was 'teaching' the physics of work, energy, power, and pressure while students were 'learning' the same; and the other one for the lessons where students were teaching to their peers and the teacher was facilitating learning and managing class. When the usual teacher centred teaching was replaced by the new one with a new set of expectations on both sides, an old contract had to be disrupted and new one which is appropriate to the reciprocal peer tutoring condition has to be redefined (Arias \& Araya, 2009; Pepin, 2014). Therefore, this was what most likely happed in the Experimental-1 class where the former teacher centred pedagogy was totally replaced by reciprocal peer tutoring. However, in the case of the two mixed classes, Experimental-2 and Experimental-3, where peer tutoring was used once and twice in every three physics lessons, the old contract was breached but not totally abandoned to be replaced by the new one. This condition might have persisted throughout the 9 weeks to confuse students about what was expected of them and what they expect from their teacher.

In Pepin (2014) studied the transformation of the didactic contract as students progress from school to university, for the case of mathematics and concluded that there would be likely to have serious consequences, and even a rapture, for students' success, or failure in their mathematics learning. In parallel to this, we conclude that in the physics lessons with mixed methods were frequently changing back and forth, there will be serious consequences for students in successfully learning physics. Hence, we may conclude based on the lack of achievement improvement in the mixing pedagogy classes, mixing the methods in ways that were requiring students to work with different contrasting didactical contract are unsuccessful. However, this conclusion would have been stronger if there were a comparison group where there was no such change of the didactic contract because the pedagogy used was not changed and the score from this class was compared with those of the mixed implementation classes.

\section{CONCLUSION}

The purpose of this study was to test the best mix of reciprocal peer tutoring with the business as usual direct teaching method to bring about improvements in students' achievement in secondary school physics in the context of content focused curriculum and high-stake examination-oriented classroom environment. More importantly, it was aspired to identify the best way of combining reciprocal peer tutoring with direct teaching for the best students learning outcome. From observation and data analysis of achievement scores of three grade 9 students in sub-urban school in Ethiopia it was found that reciprocal peer tutoring resulted in significant improvement students' physics achievement. However, due to the lack of comparison group with purely direct teacher-centred teaching, it could not be concluded that reciprocal peer tutoring was better than the direct teacher instruction as suggested in plethora of literature in the area. The second conclusion in this study was that in the special case of total usage of reciprocal peer tutoring, low achieving students were found to benefit the most from the pedagogy than higher achievers. It could also be observed that female students are who could show better progress in their achievement than male students which implies that reciprocal peer tutoring may help to reduce the learning gap between male and female students. Finally, it could be concluded that we have an indicative but not conclusive evidence in this study that the mixing of such student-centred pedagogy as reciprocal peer tutoring with a teacher dominated instruction will not be successful at least in enhancing students' physics learning. However, this cannot be concluded for any mixing of teaching pedagogy because the attempt here was limited to the mixing of reciprocal peer tutoring with direct teaching, not with any other pedagogy. Nevertheless, this conclusion needs further rechecking by including a comparison group and replication of the multi-level quasi experiment as mixing pedagogy may create confusion to students as to the re-enforced didactical contract in mixed implementation.

\section{REFERENCES}

Alemu, M., Kind, P. Tadesse, M., Atnafu, M., \& Michael, K. (2017). Challenges of Science Teacher Education in LowIncome Nations - The Case of Ethiopia. ESERA-17 conference proceedings, Dublin, Ireland.

Ambrose, S. A., Bridges, M. W., DiPietro, M., Lovett, M. C., \& Norman, M. K. (2010). How learning works: 7 researchbased principles for smart thinking. San Francisco: Jossey-Bass.

Arias, F. \& Araya A. (2009). Analysis of the didactical contracts in 10th grade math classes. Quaderni di Ricerca in Didattica (Matematica), Supplement, 4(19), 155-163. 
Beatty, A., \& Pritchett, L. (2012). From Schooling Goals to Learning Goals: How Fast can Student Learning Improve? CDG Policy Paper 012. Oxford, UK: Young Lives. Retrieved from https:/ / www.cgdev.org/sites/default/files/1426531_file_Beatty_Pritchett_Time_to_MLG_FINAL_0.pdf

Bell, S. (2010). Project-based learning for the 21st century: Skills for the future. The Clearing House: A Journal of Educational Strategies, Issues and Ideas, 83(2), 39-43. https:/ / doi.org/10.1080/00098650903505415

Benware, C. A., \& Deci, E. L. (1984). Quality of learning with an active versus passive motivational set. American Educational Research Journal, 21(4), 755-765. https:/ / doi.org/10.3102/00028312021004755

Bowman-Perrott, L. J, Burke, M. D., Zhang, N., \& Zaini S. (2014). Direct and Collateral Effects of Peer Tutoring on Social and Behavioral Outcomes: A Meta-Analysis of Single-Case Research. School Psychology Review, 43(3), 260-285. Retrieved from https://www.researchgate.net/publication/282502483

Bowman-Perrott, L. J., Greenwood, C. R., \& Tapia, Y. (2007). The efficacy of peer tutoring used in secondary alternative school classrooms with small teacher/pupil ratios and students with emotional and behavioral disorders. Education and Treatment of Children, 30, 65-87. https:/ / doi.org/10.1353/etc.2007.0014

Bryk, A., Harding, H., \& Greenberg, S. (2012). Contextual influences on inquiries into effective teaching and their implications for improving student learning. Harvard Educational Review, 82, 83-106. https:/ / doi.org/10.17763/haer.82.1.k58q7660444q1210

Cheng, Y.-C., \& Ku, H.-Y. (2009). An Investigation of the Effects of Reciprocal Peer Tutoring. Computers in Human Behavior, 25(2009), 40-49. https:/ / doi.org/10.1016/j.chb.2008.06.001

Chi, M. T. H. (2009). Active-Constructive-Interactive: A Conceptual Framework for Differentiating Learning Activities. Topics in Cognitive Science, 1(2009), 73-105. https:/ / doi.org/10.1111/j.1756-8765.2008.01005.x

Cleary, P., Gross, C., Zaslavsky, A., \& Taplin, M. (2012). Multilevel Interventions: Study Design and Analysis Issues. Journal of the National Cancer Institute Monographs, 44, 49-55. https://doi.org/10.1093/jncimonographs/lgs010

Cohen, P. A., Kulik, J. A., \& Kulik, C. C. (1982). Educational outcomes of tutoring: A meta-analysis of findings. American Educational Research Journal, 19, 237-248. https://doi.org/10.3102/00028312019002237

Dole, S., Bloom, L., \& Kowalske, K. (2016). Transforming Pedagogy: Changing Perspectives from Teacher-Centered to Learner-Centered. Interdisciplinary Journal of Problem-Based Learning, 10(1). https:/ / doi.org/10.7771/15415015.1538

Education Strategy Agency (2018). Education and Training Problems and Prospective Solutions: Discussion Paper. ESA Temporary Secretariat Office, Addis Ababa, July 2018 (Unpublished).

Fuchs, L. S., Fuchs, D., \& Karns, K. (2001). Enhancing kindergartners' mathematical development: Effects of peerassisted learning strategies. Elementary School Journal, 101, 495-510. https:/ / doi.org/10.1086/499684

Fullan, M., \& Langworthy, M. (2013). Towards a new end: New pedagogies for deep learning. Seattle, WA: Collaborative Impact. Retrieved from http://www.newpedagogies.info/wp-content/uploads/2014/01/New_ Pedagogies_for_Deep\%20Learning_Whitepaper.pdf

Gillies, R. M., \& Ashman, A. F. (2003). An historical review of the use of groups to promote socialization and learning. In R. M. Gillies \& A. F. Ashman (Eds.), Cooperative Learning: The Social and Intellectual Outcomes of Learning in Groups (pp. 1-18). London: Routledge Falmer.

Grant, M. M., \& Hill, J. R. (2006). Weighing the Risks with the Rewards: Implementing Student Centered Pedagogy within High-Stakes Testing. In R. Lambert \& C. McCarthy (Eds.), Understanding Teacher Stress in an Age of Accountability (pp. 19-42). Greenwich, CT: Information Age Press.

Handley, M., Lyles, C., McCulloch, C., \& Cattamanchi, A. (2018). Selecting and Improving Quasi-Experimental Designs in Effectiveness and Implementation Research. Annual Review of Public Health 2018, 39, 5-25. https:/ / doi.org/10.1146/annurev-publhealth-040617-014128

Hawkins, R. O., Musti-Rao, S., Hughes, C., Berry, L., \& McGuire, S. (2009). Applying a randomized interdependent group contingency component to classwide peer tutoring for multiplication fact fluency. Journal of Behavioral Education, 18, 300-318. https:/ / doi.org/10.1007/s10864-009-9093-6

Johnson, D. W., \& Johnson, R. T. (2009). Educational psychology success story: Social interdependence and theory and cooperative learning. Educational Researcher, 38(5), 365-379. https:/ / doi.org/10.3102/0013189X09339057

Johnson, D. W., Johnson, R. T., \& Smith, K. (2007). The state of cooperative learning in postsecondary and professional settings. Educational Psychology Review, 19(1), 15e29. https:/ / doi.org/10.1007/s10648-006-90388

Joshi, R. D., \& Verspoor, A. (2013). Secondary Education in Ethiopia: Supporting Growth and Transformation. Washington, DC: World Bank. https:/ / doi.org/10.1596/978-0-8213-9727-5 
Lewin, K. (2009). Access to Education in Sub-Saharan Africa: Patterns, Problems and Possibilities. Comparative Education, 45(2), 151-174. https:/ / doi.org/10.1080/03050060902920518

Maheady, L., \& Gard, J. (2010). Classwide Peer Tutoring: Practice, Theory, Research, and Personal Narrative. Intervention in School and Clinic, 46(2), 71-78. https:/ / doi.org/10.1177/1053451210376359

Miravet, L. M., Ciges, A., \& García, O. (2014). An experience of reciprocal peer tutoring at the university. Procedia Social and Behavioral Sciences, 116(2014), 2809-2812. https:/ / doi.org/10.1016/j.sbspro.2014.01.661

MOE. (2015). Education Sector Development Program V (ESDP V) 2015/2016 - 2019/2020. Addis Ababa: MOE.

Neugebauer, J., Ray, D. G., \& Sassenberg, K. (2016). When being worse helps: The influence of upward social comparisons and knowledge awareness on learner engagement and learning in peer-to-peer knowledge exchange. Learning and Instruction, 44, 41-52. https:/ / doi.org/10.1016/j.learninstruc.2016.02.007

Pepin, B. (2014). Using the Construct of the Didactic Contract to Understand Student Transition into University Mathematics Education. Policy Futures in Education, 12(5), 646-657. https:/ / doi.org/10.2304/pfie.2014.12.5.646

Piesche, N., Jonkmann, K., Fiege, C., \& Keßler, J., (2016). CLIL for all? A randomised controlled field experiment with sixth grade students on the effects of content and language integrated science learning. Learning and Instruction, 44, 108-116. https:// doi.org/10.1016/j.learninstruc.2016.04.001

Rivkin, S. G., Hanushek, E. A., \& Kain, J. (2005). Teachers, schools, and academic achievement. Econometrica, 73, 417-458. https:// doi.org/10.1111/j.1468-0262.2005.00584.x

Schleyer, G., Langdon, G., \& James, S. (2005). Peer tutoring in conceptual design. European Journal of Engineering Education, 30(2), 245-254. https:/ / doi.org/10.1080/03043790500087084

Scott, P., Mortimer, E., \& Ametller, J. (2011). Pedagogical link-making: a fundamental aspect of teaching and learning scientific conceptual knowledge. Studies in Science Education, 47(1), 3-36. https:// doi.org/10.1080/03057267.2011.549619

Semela, T. (2010). Who is joining physics and why? Factors influencing the choice of physics among Ethiopian university students. International Journal of Environmental \& Science Education, 5(3), 319-340.

Semela, T. (2014): Teacher preparation in Ethiopia: a critical analysis of reforms. Cambridge Journal of Education. https:/ / doi.org/10.1080/0305764X.2013.860080

Shibeshi, A., Mekonnen, D., Semela, T., \& Endawoke, Y. (2009). Assessment of Science Education Quality Indicators in Addis Ababa, Bahir Dar and Hawassa Universities. In Quality of Higher Education in Ethiopian Public Institutions, Forum for Socical Studies, Addis Ababa, Ethiopia.

Singh, A. (2014). Emergence and Evolution of Learning Gaps across Countries: Panel Evidence from Ethiopia, India, Peru and Vietnam, Working Paper 124. Oxford, UK: Young Lives.

Supanc, M., Vollinger, V., \& Brunstein. J. (2017). High-structure versus low-structure cooperative learning in introductory psychology classes for student teachers: Effects on conceptual knowledge, self-perceived competence, and subjective task values. Learning and Instruction, 50, 75-84. https:// doi.org/10.1016/j.learninstruc.2017.03.006

Tella, A. (2013). The Effect of Peer Tutoring and Explicit Instructional Strategies on Primary School Pupils Learning Outcomes in Mathematics. Bulgarian Journal of Science and Education Policy, 7(1), 5-25.

Topping, K. J. (2005). Trends in Peer Learning. Educational Psychology, 25(6), 631-645. https://doi.org/10.1080/01443410500345172

Topping, K. J., Dehkinet, R., Blanch, S., Corcelles, M., \& Duran, D. (2013). Paradoxical effects of feedback in international online reciprocal peer tutoring. Computers $\mathcal{E}$ Education, 61(2013), 225-231. https:// doi.org/10.1016/j.compedu.2012.10.002

Topping, K. J., Peter, C., Stephen, P., \& Whale, M. (2004). Cross-age tutoring of science in the primary school: Influence on scientific language and thinking. Educational Psychology, 24, 57-75. https:/ / doi.org/10.1080/0144341032000146449

Utley, C. A., \& Mortweet, S. L. (1997). Peer-mediated instruction and interventions. Focus on Exceptional Children, 29, 1-23. https:/ / doi.org/10.17161/fec.v29i5.6751

Vygotsky, L. S. (1978). Mind in society: The development of higher psychological processes. In M. Cole, V. John-Steiner, S. Scribner, \& E. Souberman (Eds.). Cambridge, MA: MIT Press.

Windschitl, M. (2002). Framing Constructivism in Practice as the Negotiation of Dilemmas: An Analysis of the Conceptual, Pedagogical, Cultural, and Political Challenges Facing Teachers. Review of Educational Research, 72(2), 31-175. https:/ / doi.org/10.3102/00346543072002131 
Yorges, S. L. (2008, May). Providing "realistic course previews" to enhance learning and satisfaction. APS Observer. Retrieved from http:/ / www.psychologicalscience.org/observer/getArticle.cfm?id=2347\#

Zenelia, M., Thurstonb, A., \& Rosethc, C., (2016). The influence of experimental design on the magnitude of the effect size -peer tutoring for elementary, middle and high school settings: A meta-analysis. International Journal of Educational Research, 76, 211-223. https:/ / doi.org/10.1016/j.ijer.2015.11.010

\section{http://www.ejmste.com}

